Original Research Paper

\title{
Preliminary Experimental and Finite-Element Numerical Assessment of the Structural Performance of SMA-Reinforced GFRP Systems
}

\author{
${ }^{1}$ Filipe Amarante dos Santos and ${ }^{2}$ Chiara Bedon \\ ${ }^{I}$ CERIS, ICIST, Faculdade de Ciencias e Tecnologia, Universidade NOVA de Lisboa, Portugal \\ ${ }^{2}$ DIA - Department of Engineering and Architecture, University of Trieste, Italy
}

Article history

Received: 08-08-2016

Revised: $14-08-2016$

Accepted: 26-09-2016

Corresponding Author: Chiara Bedon

DIA - Department of

Engineering and Architecture,

University of Trieste, Italy

Email: bedon@dicar.units.it

\begin{abstract}
In this study, the feasibility and potentiality of a novel design concept is explored by means of small scale experimental tests and FiniteElement numerical simulation. Taking advantage of the intrinsic potentiality of Shape-Memory Alloys wires able to work as adaptive actuators when subjected to joule heating, a 'smart-GFRP' concept consisting in Glass-Fiber-Reinforced-Polymer (GFRP) structural members with a SMA reinforcement is preliminary assessed. As shown, as far as the working temperature increases, important structural benefits can be achieved in terms of overall performance of the proposed composite systems. The potentiality of the same design concept is then further assessed by means of a practical calculation example.
\end{abstract}

Keywords: Shape-Memory Alloys (SMA), Glass-Fiber Reinforced Polymer (GFRP), Composite Systems, Smart-GFRP Design Concept, Active Control Systems, Experimental Tests, Finite-Element Numerical Modelling

\section{Introduction}

Glass-Fiber Reinforced Polymer (GFRP) materials are becoming increasingly popular in civil engineering applications due to their high structural performances in this field, which are mostly associated with their light-weight, high strength and non-corrosion properties (see Fig. 1). Their durability and low maintenance are being explored by civil engineers to extend the life of existing structures, especially in the form of retrofitting techniques for existing reinforced concrete, steel or masonry buildings (see for example Benmokrane et al., 1995; Zou et al., 2007; Alaedini et al., 2015; Gattesco et al., 2015, etc.), but also in innovative, light-weight and competitive design solutions for new constructional systems (see for example Gonilha et al., 2013; Panigrahi and Rashmi, 2016; Yang et al., 2016; Valarinho et al., 2013, etc.).

This low-cost composite material is built up of high strength glass fibers, providing strength and stiffness and a polymer resin (polyester, vinylester or epoxy), which acts as a matrix to offer protection and promotes the load transference between fibers. One of the major drawbacks of GFRP materials is their high vulnerability to moderately high temperatures, with obvious effects for structural application in Civil Engineering buildings and infrastructures (Robert and Benmokrane, 2010; Foster and Bisby, 2008; Kodur et al., 2007; Cao et al., 2009, etc.).

In fact, although glass fibers - as inorganic compounds - are very stable and mostly insensitive to temperature variations, the mechanical properties of polymeric resins rapidly decrease above a critical temperature $\left(T_{c r}\right)$, comprised in the glass-transition temperature range $\left(T_{g}\right)$ of the resin. Some of the GFRP properties that suffer an important degradation associated with higher temperatures are the ultimate stress (both in tension and compression) and modulus of elasticity.

As typical $T_{g}$ values for polyester resins lie within $60-170^{\circ} \mathrm{C}$, in this regard, the structural behavior of GFRP elements may be compromised even for service loading scenarios, when the working temperature reaches this temperature threshold.

Compared to GFRP, Shape-Memory Alloys (SMA) are a class of metal materials that exhibit two outstanding properties, namely the superelastic and the Shape-Memory Effects (SME). Superelasticity (SE) is associated to the capacity of these materials to recover from high imposed strains (up to 8\%) with no residual deformations, while developing a hysteretic-cycle. The SME allows the material to return to its original shape, upon permanent deformation, through a heat-cycle. 


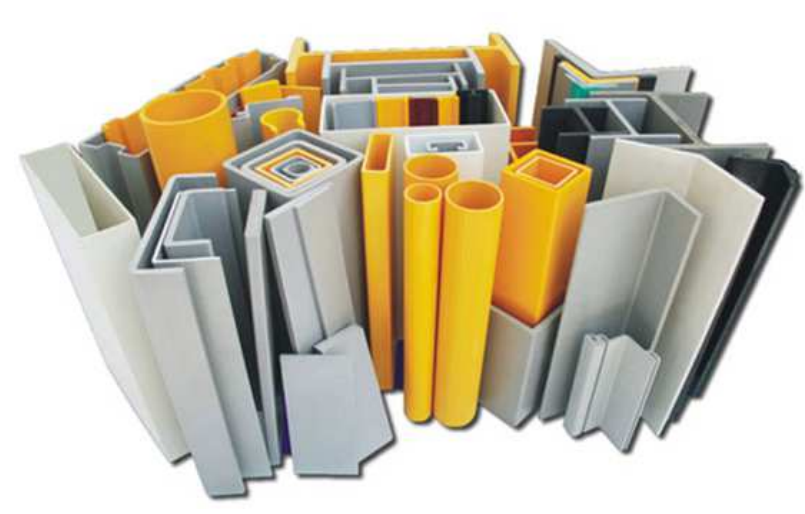

Fig. 1. Examples of pultruded profiles for structural applications

These properties are due to the ability of SMAs to develop martensitic transformations, which are solid state, diffusionless transformations between high energy and low energy crystallographic phases, e.g. the austenitic and the martensitic phases, respectively.

Due to their intrinsic mechanical properties, SMAs have been largely used for Civil Engineering buildings and infrastructures in the form of active control systems in general (see Boroschek et al., 2007; Dolce and Cardone, 2005; Mc Cormick et al., 2006; Zhang and Zu, 2007; Shook et al., 2008; Wilde et al., 2000; Andrawes and Des Roches, 2007; Tamai et al., 2003; Savi et al., 2011, etc.).

In this context, the main objective of the present research activity is to explore the concept of an adaptive reinforcement system for GFRP structural members built up of heat activated martensitic SMA wires, highlighting the possible structural benefits and overall effects of the proposed composite system. This design concept is in line with recent SMA applications in traditional structural glazing system solutions (Bedon and dos Santos, 2016; dos Santos et al., 2016a; 2016b).

\section{The 'Smart-GFRP' Concept}

The proposed smart-GFRP concept is based on thermally driven shape-memory based wire actuators, with the ability of exerting significant forces as the temperature of the SMA elements rises above the $A_{s}$ temperature, which is the temperature associated with the beginning of the transformation between the martensitic and austenitic phases.

By incorporating SMA actuating wires in the GFRP elements, the aim of this research activity is to explore the feasibility and possible advantaged deriving from this post-tensioning effect, in order to mitigate the adverse effects associated to higher temperatures in these materials. As the austenitic phase of the SMA actuators is also stiffer than its martensitic counterpart, some additional compensation for the degradation of the GFRP elastic modulus is also provided to the composite system, as the temperature of the system rises.
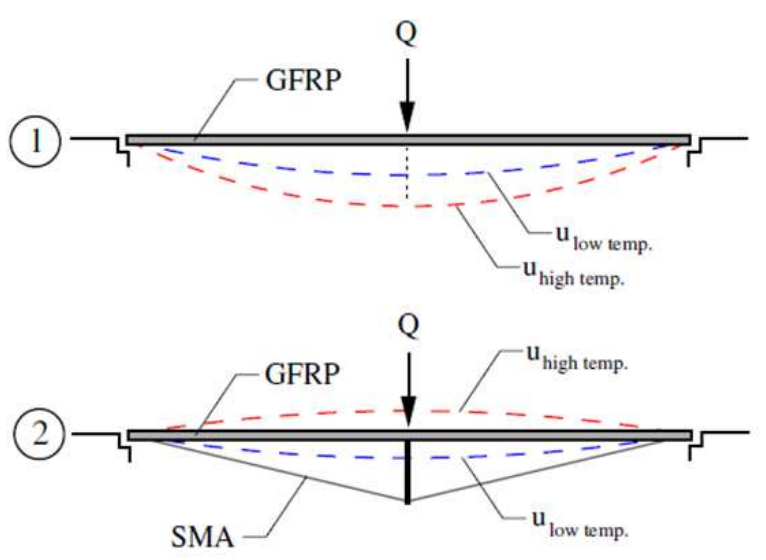

Fig. 2. General expected behavior of the proposed 'smartGFRP' structural element, under different temperature scenarios. Legend: $1=$ unreinforced GFRP system; 2 = SMA-reinforced GFRP system

In Fig. 2, a qualitative comparison between the behavior of the proposed smart GFRP concept and the unreinforced solution is shown, when subjected to a temperature variation. In the proposed example, compared to the reference GFRP beam, the reinforced GFRP solution includes an additional SMA wire actuator with a triangular configuration. Both the systems are subjected to a mid-pan point load $Q$, leading to a maximum deflection $u_{\text {low temp }}$ under low temperatures. As the SMA-reinforced system is stiffer, due to the additional contribution provided by the cable, the corresponding maximum deflection is still lower than its unreinforced counterpart. As the temperature rises above $T_{c r}$ and the elastic modulus of the unreinforced beam degrades, however, the displacement field associated to the assigned $Q$ load markedly increases, reaching the final value $u_{\text {high temp }}$.

This is not the case of the SMA-reinforced GFRP system, in which - due to the combined effects deriving from the thermal activation of the SMA wires as well as from the additional stiffening contribution of the cables - the system is able to compensate for the degradation of the elastic modulus of the GFRP beam, hence resulting in a marked mitigation of the maximum expected deflections.

\section{Research Objectives and Strategy}

In order to assess the feasibility and potentiality of the proposed concept, a preliminary experimental and Finite-Element numerical investigation is first carried out on some selected geometrical and mechanical configurations of smart-GFRP systems.

The experimental mechanical calibration of SMA wires is first carried out, being the material properties as a function of temperature representative of a key input parameter. Two configurations of small 
prototypes are then experimentally investigated, under the action of an external load and an assigned temperature variation. In this manner, Finite-Element models able to take into account the actual material properties and mechanical interaction between the assembly components are properly validated.

Based on the so obtained experimental results and calibrated Finite-Element models implemented in ABAQUS (Simulia, 2012), the parametric numerical study and design concept is then further extended to a practical case of technical interest (i.e. a footbridge application), in order to first estimate the potentiality and feasibility of the smart-GFRP solution. Based on a critical discussion of the collected parametric results and on the current outcomes, it is expected that the proposed design concept could be further extended and improved.

\section{Experimental Mapping of the SMA Elastic Modulus as a Function of Temperature}

A small scale experimental prototype was first built to perform the mapping of the elastic modulus of a SMA wire as a function of temperature. This mapping consists on the evaluation of the elastic modulus of a SMA wire subjected to a wide range of temperatures. The temperature modulation of the SMA wire is achieved by Joule heating. By subjecting the wire to increasing stress levels, while screening the corresponding strains, it is possible to have a good estimate of the tangent elastic modulus associated with a given temperature and stress level. The NiTi SMA element is a straight, oxide free, martensitic wire, with $0.5 \mathrm{~mm}$ diameter and was provided by Dynalloy, Inc. A $5 \%$ memory strain can be obtained when the SMA wire is heated above the $A_{s}$ transformation temperature. The SMA wire is attached to a main frame, as shown in Fig. 3.

A Baumer Photoelectric sensor CH-8501 Class 2 laser was used to monitor the length variations experienced by the SMA wire throughout the experimental procedure. The verticality of the applied loads was controlled by a leveler. A Sorensen programmable DC power supply, model XHR 40-25, was used to allow the Joule heating of the NiTi wire, which was performed in a voltage control mode, with a maximum input current of $2 \mathrm{~A}$.

The temperature of the NiTi wire and the room temperature were monitored by two T-type thermocouples (Copper-Constantan), with a temperature reading range of $-40^{\circ} \mathrm{C}$ to $100^{\circ} \mathrm{C}$, connected to a NI SCXI-1112 8 channel thermocouple amplifier. The general platform for the data acquisition and control is a NI PXI-1052. A DAQ assistant express VI, using NIDAQmx software, was used to create, edit and run the analog inputs corresponding to the voltage measurement tasks. Using an averaging process, a sample compression of the data points was performed in order to attenuate the noise derived from the readings.

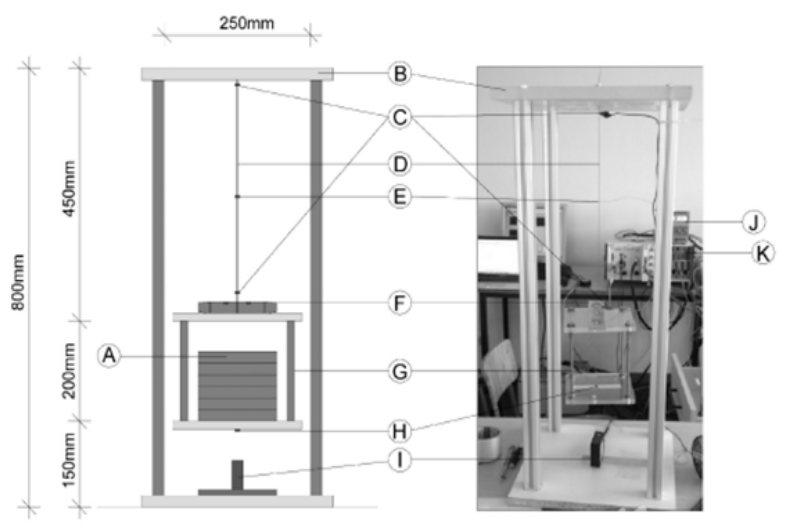

Fig. 3. Experimental prototype for the $E_{S M A}$ mapping. Legend: $\mathrm{A}=$ weights; $\mathrm{B}=$ main frame; $\mathrm{C}=$ electrical connectors; $\mathrm{D}=\mathrm{SMA}$ wire; $\mathrm{E}=$ thermocouple; $\mathrm{F}=$ leveler; $\mathrm{G}=$ weight support; $\mathrm{H}=$ laser target; $\mathrm{I}=$ laser sensor; J= DC power supply; K= NI-DAQ platform

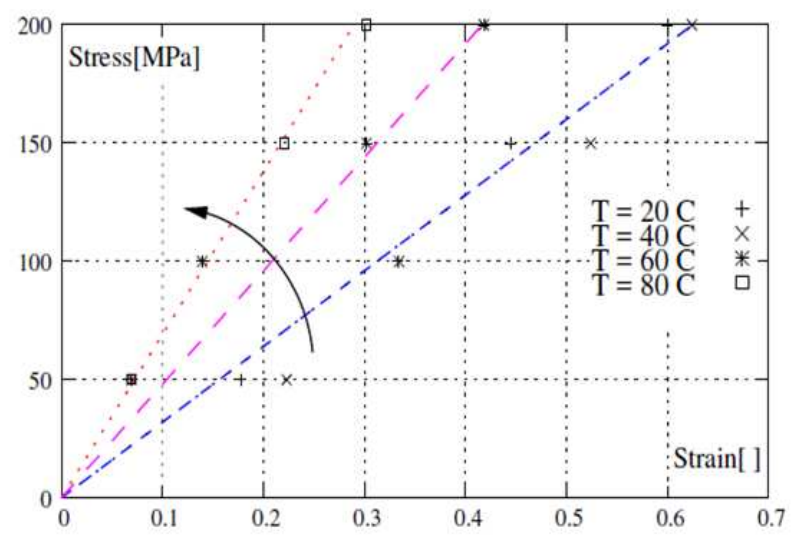

Fig. 4. Experimental stress-strain diagram for the single SMA wire specimen, as a function of temperature, as obtained at imposed stress levels (range: 50MPa200MPa)

A closed-loop control system based in a proportional plus Integral Plus Derivative (PID) controller was used to set the temperature in the SMA wire.

In Fig. 4 are presented the experimental stress-strain diagrams, as obtained for the four tested temperatures, which ranged from $20^{\circ} \mathrm{C}$ to $80^{\circ} \mathrm{C}$ with a $20^{\circ} \mathrm{C}$ increment. The SMA wire was subjected to four stress levels, i.e. $50 \mathrm{MPa}, 100 \mathrm{MPa}, 150 \mathrm{MPA}$ and $200 \mathrm{MPa}$, as the corresponding strain levels were assessed.

As shown in Figure 4, the relationship between stress and strain can be accurately approximated by linear regressions, for all the tested temperatures. The final result is an elastic modulus $E_{S M A}$ ranging from $E_{S M A, 20}=$ $32 \mathrm{GPa}$ to $E_{S M A, 80}=69 \mathrm{GPa}$, which represent the martensitic and austenitic elastic modulus of the SMA specimen, respectively $\left(E_{S M A, 40}=32 \mathrm{GPa}\right.$ and $E_{S M A, 60}=$ $48 \mathrm{GPa}$ the intermediate values). 


\section{Experimental Investigation on a Small Prototype of SMA-Reinforced GFRP Beam}

\section{Test Setup and Methods}

An additional small scale experimental prototype was built to evaluate the overall increase in the deformations shown by simply supported GFRP beams, subjected to vertical loads at mid-span, when affected by a controlled temperature variation.

The typical GFRP beam consisted of a $20 \mathrm{~mm} \times 175 \mathrm{~mm}$ plate, $2 \mathrm{~mm}$ in thickness, see Fig. 5 . The GFRP beam was then reinforced with SMA wires, in order to improve the overall performance under high temperatures and namely to limit the deformation increase. The typical NiTi SMA wire was a straight, oxide free, martensitic specimen (at ambient temperature), with $0.5 \mathrm{~mm}$ diameter, as provided by Dynalloy, Inc.

In them, a $5 \%$ memory strain can be obtained when the SMA wire is heated above the $A_{f}$ transformation temperature.

In addition to the unreinforced GFRP specimen ('S0', in the following), a triangular layout was taken into account for the SMA wire, with $e_{S M A}=19 \mathrm{~mm}$ the total length of the mid-span deviator. Figure 5 presents a schematic overview of the S1 geometrical properties.

Through the full experimental investigation, the maximum deflections of the $\mathrm{S} 0$ and $\mathrm{S} 1$ specimens due to a mid-span weight of $5 \mathrm{~N}$ were monitored at different working temperatures (range $20^{\circ}-80^{\circ} \mathrm{C}$ ). In doing so, the test setup consisted of a main suspension frame, which enabled to immerse the GFRP beam specimens in a temperature controlled water tank. The vertical mid-span displacement was monitored by means of a Baumer Photoelectric sensor CH-8501 Class 2 laser, as in the case of the single SMA wire specimen. A self-made clamping system was then used to restraint the GFRP beams ends, see Fig. 6 .

During the experiments, as in the case of the single SMA wire specimen, the temperature of the NiTi wires and the water tank were monitored by two T-type thermocouples (Copper-Constantan), with a temperature reading range of $-40^{\circ} \mathrm{C}$ to $100^{\circ} \mathrm{C}$, connected to a NI SCXI-1112 8 channel thermocouple amplifier. The general platform for the data acquisition and control consisted then in a NI PXI-1052 system. A DAQ assistant express VI, using NI-DAQmx software, was used to create, edit and run the analog inputs corresponding to the measurement tasks. Using an averaging process, a sample compression of the data points was also performed in order to attenuate the noise derived from the readings.

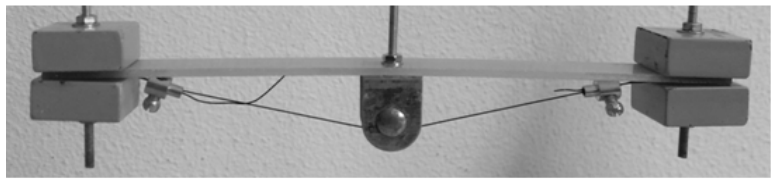

(a)

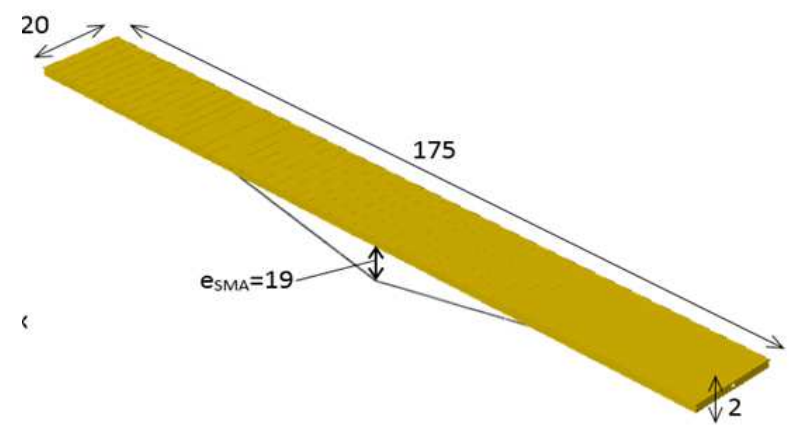

(b)

Fig. 5. Overview of the S1 small scale experimental prototype, (a) lateral view of the specimen and (b) schematic axonometry, with nominal dimensions in $\mathrm{mm}$

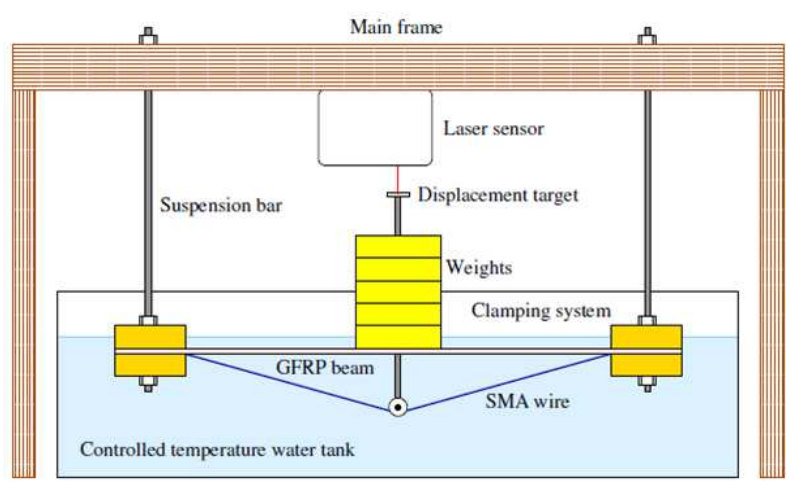

(a)

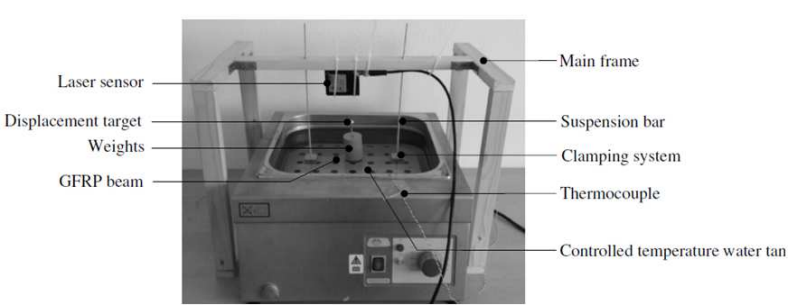

(b)

Fig. 6. Experimental test setup for the small prototypes, with (a) schematic lateral view and (b) axonometry

\section{Experimental Results}

The maximum deflections experimentally measured for the S0 and S1 specimens are proposed in Fig. 6, as obtained within the range of assigned temperatures. In accordance with the setup and loading scheme of Fig. 6, positive deflection values in Fig. 7 are representative of downward displacements for the prototypes. 


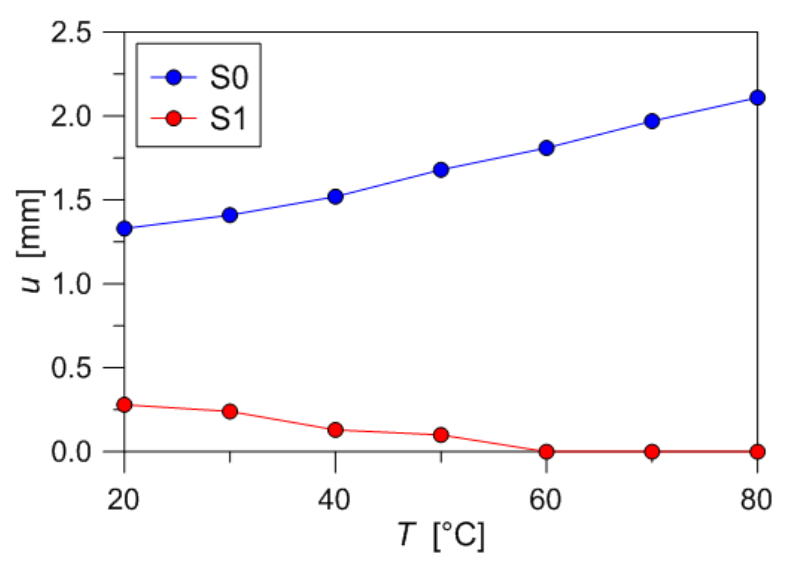

Fig. 7. Small scale experimental results for the S0 and S1 prototypes. Mid-span vertical deflection as a function of temperature

As shown, the effect of the assigned SMA reinforcement can be clearly noticed in terms of maximum deflection decrease. At room temperature, the primary effect of the SMA reinforcement derives from the additional stiffness term the wires provide to the unreinforced system. As far as the assigned temperature increases and exceeds $50-60^{\circ} \mathrm{C}$, however, the thermal activation of the SMA reinforcement further exhibits an additional beneficial effect for the unreinforced system, with maximum decrease of the measured deflections.

From Fig. 7, in this regard, it can be noticed that starting from $60^{\circ}$ the expected deflection for the S1 specimen due the assigned mid-span load is fully opposed by the SMA bracing system.

\section{Preliminary Finite-Element Numerical Investigation on Small Scale Prototypes}

In order to perform an extended parametric FiniteElement numerical investigation on selected smartGFRP systems, a preliminary FE study was first carried out. In doing so, the calibration and validation of the modelling assumptions and material mechanical properties was carried out on the base of the small scale experimental results. Static incremental, geometrical nonlinear, load controlled simulations were carried out for all the FE models.

\section{FE Model Assembly}

Two geometrically simplified but efficient FE models representative of the S0 and S1 small scale specimens were implemented in the ABAQUS (Simulia, 2012) computer software.

In the case of the unreinforced specimen, the corresponding M0 FE-model consisted of a GFRP beam composed of monolithic shell elements (S4R type available in the ABAQUS library), with $2 \mathrm{~mm}$ their nominal thickness. In accordance with the test setup of Fig. 6, the GFRP beam was clamped at the ends and subjected to a mid-span vertical load $F=5 \mathrm{~N}$. In doing so, careful consideration was paid to the calibration of the rotational restraint provided by the experimental clamping system, i.e. in the form of properly calibrated rotations springs. A regular mesh pattern composed of 4node elements was assigned to the GFRP beam, with $1.5 \mathrm{~mm}$ the average element size.

In the case of the S1 specimen, the corresponding M1 model was characterized by the presence of additional SMA wires and appropriate mechanical constraints, so that the actual interaction between the SMAs and the GFRP beams could be properly taken into account. The SMA reinforcement, in particular, consisted of B31 type beam elements with circular cross-section $(0.5 \mathrm{~mm}$ the nominal diameter). The SMA beam elements were then joined at the beam ends and further restrained via a fully rigid, mid-span deviator $\left(e_{S M A}=19 \mathrm{~mm}\right.$, see Fig. 5), numerically implemented in the form of a link constraint available in the ABAQUS library.

\section{FE Model Calibration and Validation}

Through the FE study, a key role was then assigned to the mechanical calibration of the material properties, namely GFRP and SMA, so that the structural performance of the M0 and M1 models under an assigned temperature variations and external mid-span load could be properly reproduced. For both the materials, a linear elastic constitutive law was taken into account, i.e. in order to assess - at the current stage of the research study - the elastic performance only of the so assembled FE models. The unreinforced M0 model was first investigated and calibrated. For the GFRP, the Poisson' ratio was set equal to $v_{G F R P}=0.3$. At room temperature $\left(T=20^{\circ} \mathrm{C}\right)$, the nominal modulus of elasticity provided by the producer was taken into account $\left(E_{G F R P}=\right.$ $23 \mathrm{GPa}$ (Fiberlines Composites A/S)). The calibration of the $E_{G F R P}$ values associated to a given temperature higher than $20^{\circ} \mathrm{C}$, subsequently, was numerically derived from fitting curve of the experimental deflections obtained for the S0 specimen (see Fig. 8). The so defined $E_{G F R P}$ calibration approach and solving method was first taken into account for the M0 model only, without any SMA reinforcement and then further extended/ validated towards the M1 expected deflections. In this latter case, careful consideration was paid also to the SMA mechanical properties, while using for the GFRP beam the same elastic modulus values derived from the M0 model, see Fig. 8. In terms of SMAs, a Poisson coefficient $v_{S M A}=0.3$ was used, with the $E_{S M A}=f(T)$ values numerically calibrated on the base of the experimental measurements provided in Fig. 4. 


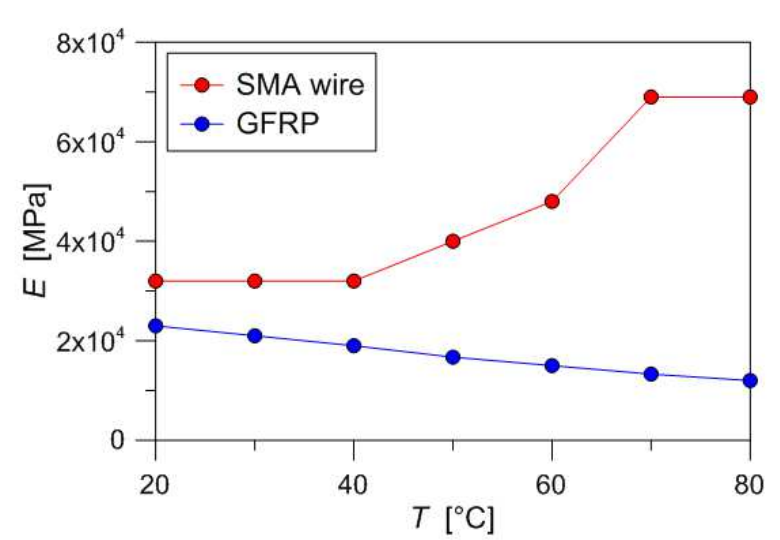

Fig. 8. Variation of the modulus of elasticity of a SMA wire (experimental values) and for GFRP (as numerically derived from ABAQUS (Simulia, 2012)), as a function of temperature

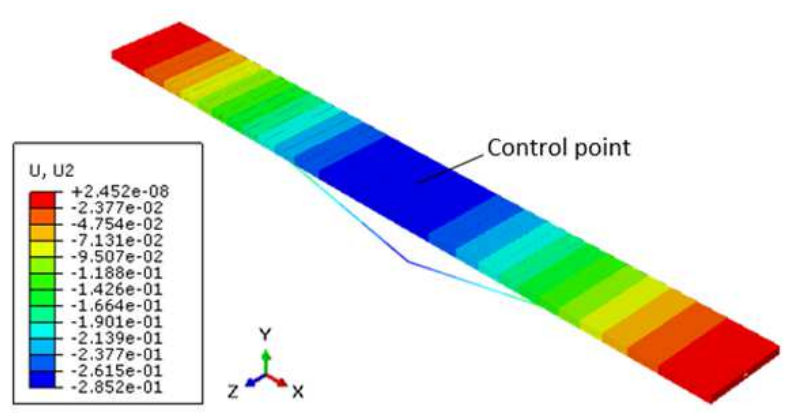

Fig. 9. Deformed configuration for the $\mathrm{M} 1$ model, $T=20^{\circ} \mathrm{C}$. Contour-plot of maximum deflections, with values expressed in millimeters (ABAQUS (Simulia, 2012))

Under a certain temperature increase, the main feature of the used SMA wires is represented by the well-known transformation phase and increase of the reference modulus of elasticity $E_{S M A}$, with implicit increase of initial strains due to heating only, i.e. in the form of a pre-stressing phenomena. Knowing the level of strain $\varepsilon_{T}$ in the SMA samples due to the assigned temperature increase only, within the experimentally explored range of $20^{\circ}-80^{\circ} \mathrm{C}$, the experimental initial strain value $\varepsilon_{T}=f(T)$ was preliminary imposed in the FE wires in the form of a predefined field state and considered as a reference configuration for the subsequent bending test. An appropriate fine-tuning of the M1 model under various temperatures was then carried out, based on the numerical fitting of the experimental mid-span deflections for the S1 sample, as also discussed in the following sections.

Figure 8, in this context, presents the FE numerically derived $E_{G F R P}$ values, together with the $E_{S M A}$ values taken into account from the experimental characterization of the single SMA wire (Fig. 4). As shown, as far as the temperature exceeds $20^{\circ} \mathrm{C}$, an almost linear decrease is expected for $E_{G F R P}$, within the range of temperatures considered through the experimental investigation.

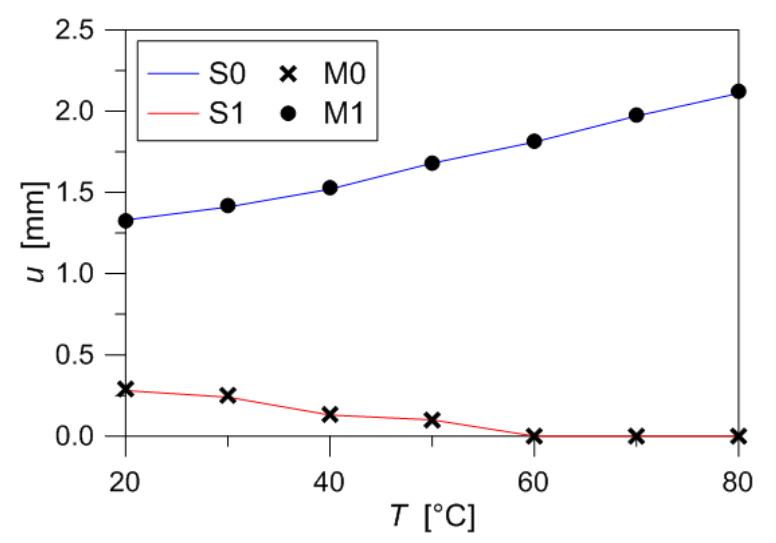

Fig. 10. Experimental and numerical (ABAQUS (Simulia, 2012)) mid-span deflections for the SMA-reinforced GFRP beam (S1 specimen) under increasing temperatures

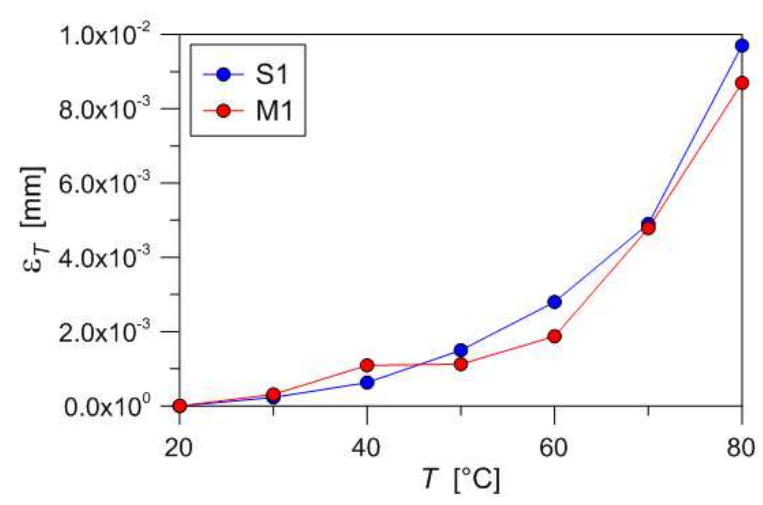

Fig. 11. Experimental and numerical (ABAQUS (Simulia 2012)) maximum strains in the SMA wire due to temperature variations, for the $\mathrm{S} 1$ specimen/M1 model under a mid-span load $F=5 \mathrm{~N}$

The FE numerical investigation carried out on the M1 model further emphasized the beneficial contribution of the SMA reinforcement (as also highlighted from the preliminary small scale experiments). At the same time, the M1 simulations confirmed the appropriate M0 calibration for the $E_{G F R P}$ values at high temperatures. Negligible variations in terms of initial strains for the SMA reinforcement were then taken into account to obtain the same experimental deflection values, hence further suggesting the correctness of the FE approach.

The typical deformed shape of the SMA reinforced, M1 FE model is in fact proposed in Fig. 9, while Fig. 10 presents the variation of maximum deflections as a function of the assigned temperature. In the same figure, the M1 FE values are compared with the M0 deflections and the corresponding S0-S1 specimens. As shown, based on the materials characterization and on fitting curve of the experimental deflections, a rather optimal agreement was found in terms of experimental and numerical mid-span deformations, see Fig. 10. 


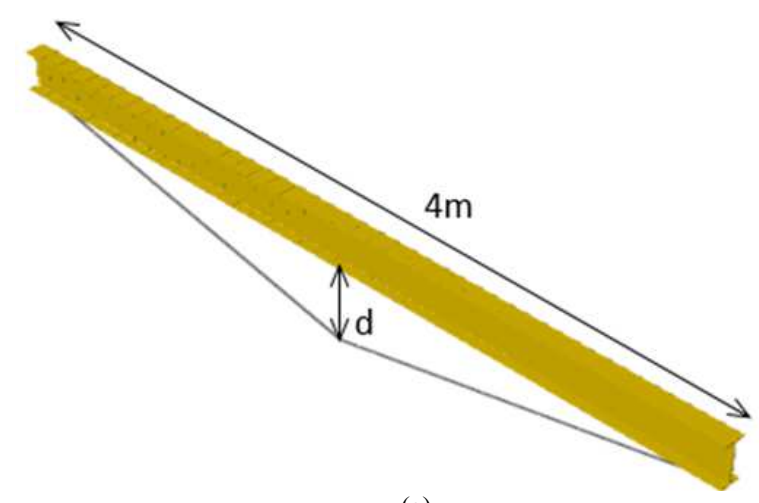

(a)

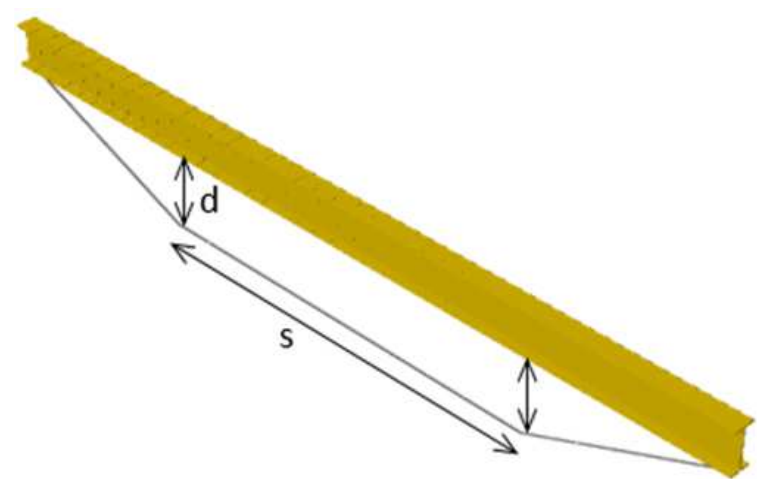

(b)

Fig. 12. Examples of (a) triangular or (b) polynomial configurations for the SMA reinforcement (ABAQUS (Simulia 2012))

Rather close correlation was also found in terms of maximum strains in the M1 model SMA-reinforcement, due to temperature increases only, see Fig. 11. Small deviations from the expected experimental measurements were observed in the range comprised between $40^{\circ}$ and $60^{\circ} \mathrm{C}$. In any case, the overall correlation between FE and corresponding test data was considered satisfactory for the purpose of the current research study, hence suggesting the extension of the same FE modelling assumptions to other structural systems of technical interest.

\section{Application of the Smart-GFRP Design Concept to a Practical case Study}

\section{Reference System and FE Solving Approach}

The smart GFRP concept was further extended and numerically investigated by taking into account a a practical case study of technical interest for designers. The reference system consisted of a pedestrian footbridge composed of 2 main GFRP girders (IPE200 profiles), simply supported at the ends of their total span (4m) and supporting a $1.2 \mathrm{~m}$ wide GFRP slab. Under service conditions, the GFRP slab is subjected to a uniformly distributed service load $q=1.2 \mathrm{kN} / \mathrm{m}^{2}$. The single GFRP girder is thus subjected to a uniform load $p=0.72 \mathrm{kN} / \mathrm{m}$.
Through the parametric study, several geometrical configurations were taken into account and the maximum effects of the assigned service load on a single GFRP girder were explored.

First, the traditional, unreinforced GFRP beam (B0 model, in the following) was investigated under increasing temperatures. The potential of a SMA reinforcement was then assessed and critically discussed based on a parametric study and on a further geometrical optimization process for the SMAreinforcement layout. Both triangular (i.e. Fig. 12a) and polynomial (Fig. 12b) configurations for the wires were considered, so that the combined stiffening and pre-stressing SMA contributions on a large-scale GRFP member could be properly assessed.

As a result, the structural performance of the reference B0 system was compared with six possible SMAreinforcement scenarios, see Table 1 . In doing so, the FE model assembly, calibration and mechanical interactions were implemented as in the case of the S0 and S1 smallscale specimens. The exception was represented by the SMA wires only, considered for the specific calculation example with a nominal diameter of $4 \mathrm{~mm}$.

\section{Discussion of FE Results}

As in the case of the S0 and S1 small scale specimens, the maximum deflection of the GFRP girder was considered as reference parameter for the comparative study. The $B_{i}$ systems presented in Table 1, under the assigned distributed service load $p$, were thus subjected to temperature variations comprised between $20^{\circ}$ and $80^{\circ} \mathrm{C}$.

Figure 13 presents the typical increase of mid-span deflections as a function of temperature, for the unreinforced $\mathrm{B} 0$ and $\mathrm{B} 1$ reinforced configurations respectively. In the Figure, positive deflection values are representative of downwards deflections for the GFRP girder. It should also be noticed, in this regard, that the absolute deflection values are collected in the figure, hence both the downward (i.e. positive, based on the assumed reference system) deformation due to the assigned service load as well as the pre-stressing effect deriving from the SMA wire activation (i.e. negative, upward deflection) are included in them.

In this sense, it is expected that as far as the temperature increases and the SMAs are activated, the pre-stressing effect magnifies in the form of a progressively increasing initial 'negative' bow for the girder (see also Fig. 2) and that the SMA bracing system would be as efficient as the temperature is high.

As shown in Fig. 13 for the B0 system, as expected, the effect of increasing temperatures and degrading mechanical properties for the GFRP girder typically manifests in fact in a marked increase of the achieved deflections, i.e. in the order of $\approx 1 / 230$ the total span at $20^{\circ} \mathrm{C}$ and gradually increasing up to $\approx 1 / 125$ the girder span at $80^{\circ} \mathrm{C}$. 


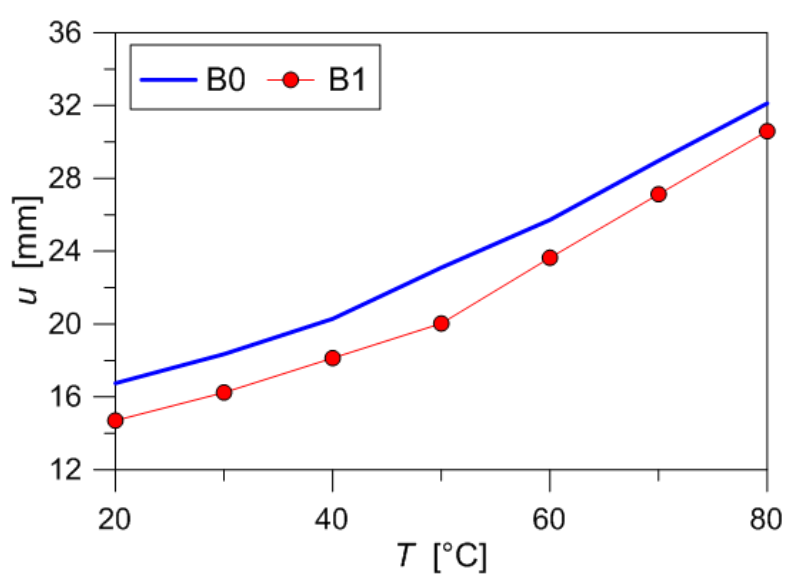

Fig. 13. Mid-span deflection of the $\mathrm{B} 0$ and $\mathrm{B} 1$ systems under the assigned service load, as a function of temperature (ABAQUS (Simulia 2012))

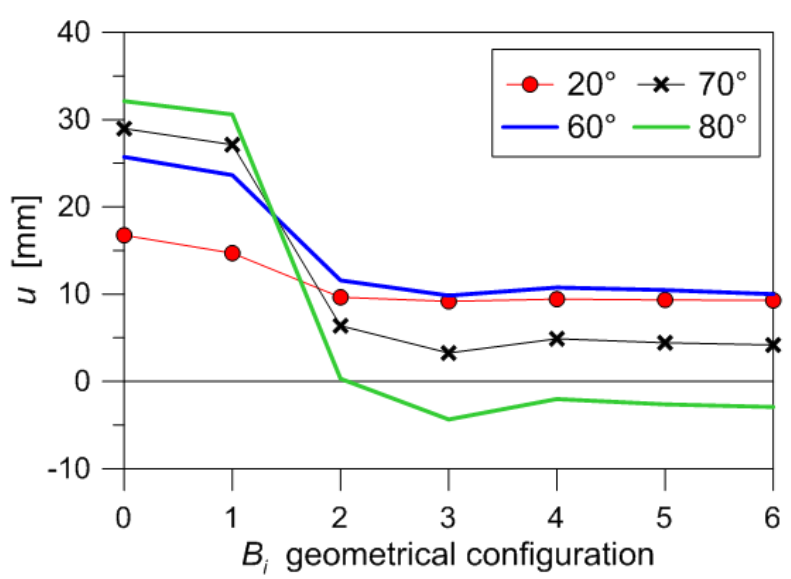

(a)

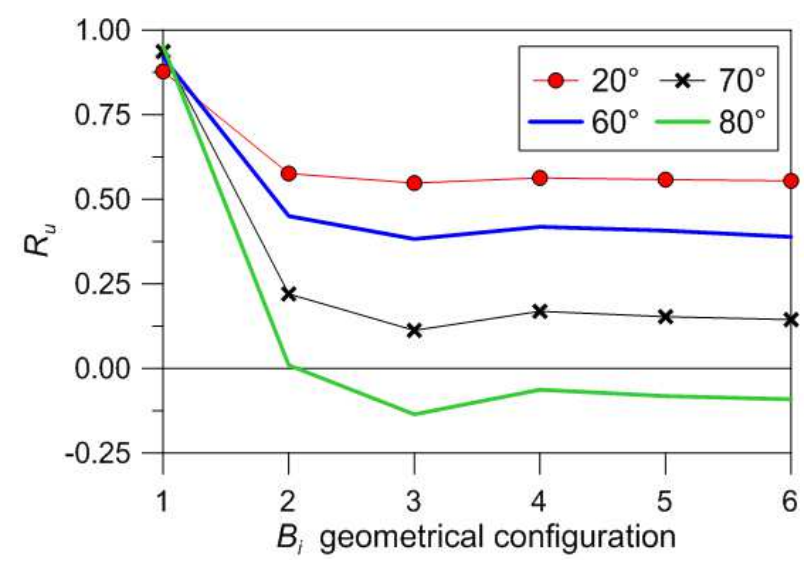

(b)

Fig. 14. Mid-span deflections for the B0 unreinforced and B1to-B6 SMA-reinforced systems. (a) Absolute deflection values and (b) absolute deflection ratio $R_{u}$ (Equation 1), as a function of temperature (ABAQUS (Simulia 2012))
Table 1. Geometrical configurations for the SMA layout optimization (ABAQUS (Simulia 2012)). Legend: $\mathrm{T}=$ triangular layout, $\mathrm{P}=$ polynomial

\begin{tabular}{llll}
\multicolumn{5}{c}{ Legend: $\mathrm{T}=$ triangular layout, $\mathrm{P}=$ polynomial } \\
\hline Model \# & $\begin{array}{l}\text { SMA } \\
\text { reinforcement }\end{array}$ & $\begin{array}{l}\mathrm{d} \\
{[\mathrm{mm}]}\end{array}$ & $\begin{array}{l}\mathrm{s} \\
{[\mathrm{mm}]}\end{array}$ \\
\hline B0 & - & - & - \\
\hline B1 & $\mathrm{T}$ & 200 & - \\
B2 & & 400 & - \\
B3 & & 600 & - \\
\hline B4 & P & 400 & 1000 \\
B5 & & & 1500 \\
B6 & & & 2000 \\
\hline
\end{tabular}

The B1 SMA-reinforcement provides a partial mitigation only of temperature increase effects, i.e. manifesting a rather visible limitation of deflections (due to the additional stiffening contribution of the wires) but without fully exploiting the adaptive effect of SMAs activation, i.e. for temperatures higher than $50^{\circ} \mathrm{C}$.

In this context, a further comparative study was carried out in ABAQUS by considering all the parametric data derived from the full exploratory investigation (Table 1), both in dimensional and non-dimensional form. obtained data in non-dimensional form.

Figure $14 \mathrm{a}$ presents in fact the variation of the midspan deflections for the B0-to-B6 systems, as a function of a given temperature (with evidence of $\mathrm{FE}$ results derived at $20^{\circ}, 60^{\circ}, 70^{\circ}$ and $80^{\circ} \mathrm{C}$ respectively). In Fig. $14 \mathrm{~b}$, the same deflection values are proposed in nondimensional form, in terms of a $R_{u}$ ratio defined as:

$$
R_{u}=R_{u}(T)=\frac{u_{B i}}{u_{B 0}}, \quad i=1, \ldots, 6
$$

As in the case of Fig. 13, the absolute deflection values are taken into account in these latter plots, with positive deflections/ratios denoting downward deformations for the examined systems.

In terms of geometrical optimization of the SMAs layout, some practical suggestions can be derived from Fig. 14. It is possible to notice, for example, that the $R_{u}$ ratios calculated for the B1 configuration (Eq.(1)) are almost in the range of $\approx 0.9$ for all the examined temperature scenarios (see Fig. 14b). This finding confirms the comparison of Fig. 13, as well as the almost stiffening effect only due to the B1 triangular layout.

From the same Fig. 14 it can be in fact observed that the polynomial layout generally provides an optimal bracing effect for the examined beam, i.e. stiffening and pre-stressing contribution effects, independently on the interspacing $s$ of the deviators, see the B4, B5 and B6 configurations. As far as the temperature increases from $20^{\circ} \mathrm{C}$, in general, the activation of the SMA wires further exploits the beneficial effects in the form of further mitigation of the assigned service loads, hence allowing a more pronounced deflection limitation at highest temperatures, ad this effects can be mainly appreciated for 
the B4 to B6 configurations, as well as for the B2 layout. Interesting effects can be achieved for the triangular configurations, see B2 and B3, as far as an appropriate distance is taken into account for the deviators.

For all the SMA-reinforced systems subjected to $80^{\circ} \mathrm{C}$, in this context, it is interesting to notice that as far as the SMA layout is optimized, the combined stiffening and pre-stressing effects deriving from the SMA wires themselves are so evident that the expected downward deflection due to the assigned service load $p$ is fully opposed by the active bracing system. This finding, in agreement with the small-scale experimental observations, further enforces the potentiality of the examined design concept, hence suggesting further extended investigations towards its full optimization.

\section{Conclusion}

In this study, an exploratory experimental and Finite-Element (FE) numerical investigation has been carried out, in order to assess the feasibility and potentiality of a novel 'smart-GFRP' design concept. The solution consists in a traditional GFRP structural member and a Shape Memory Alloy (SMA) reinforcement able to provide enhanced structural performances under high temperatures.

As far as the GFRP mechanical properties are in fact susceptible to temperature increases, the additional SMA-reinforcement components provide a double beneficial effect for a given GFRP traditional system. First, a stiffness contribution is introduced in the unreinforced system, hence a certain enhancement of structural performances is still rationally expected.

The major advantage of the proposed SMA wires is then exploited especially at high temperatures, where the thermal activation of the SMA wires themselves manifests in the form of an adaptive actuator able to provide a certain pre-stressing effect to the GFRP unreinforced system. The result is consequently an 'active' composite system in which the effects due to the assigned design loads (i.e. the maximum deflections, in this investigation) are markedly mitigated.

In this study, the potentiality of the proposed design concept was first explored at a small scale level, by means of experimental prototypes as well as fine-tuned FE models. The same design approach was then extended to a practical calculation example of technical interest and further validated based on extended FE parametric investigations. It is expected, based on the current outcomes, that the smart GFRP solutions could be further investigated and fully optimized.

\section{Acknowledgement}

The COST Action TU1403 "Adaptive Facades Network" (2014-2018, www.tu1403.eu) is gratefully acknowledged for facilitating the ongoing networking and cooperation between the Authors.
Mr. João Nunes e Mr. Filipe Silva (Universidade NOVA de Lisboa) are also acknowledged for the support during the experimental phase.

\section{Author's Contributions}

Filipe Amarante dos Santos: Design concept, experimental tests on small prototypes and data interpretation, paper writing and critical review of its scientific content.

Chiara Bedon: Calibration of Finite-Element models to the experimental test results, Finite-Element numerical simulations and data interpretation, FE case study, paper writing and critical review its scientific content.

\section{Ethics}

This article is original and contains unpublished material only. The corresponding author confirms that all the authors have read and approved the manuscript and no ethical issues are involved.

\section{References}

Alaedini, S., M.Z. Kabir and H. Hejabi, 2015. Seismic ductility evaluation of shear-deficient RC frames strengthened by externally bonded CFRP sheets. KSCE J. Civil Eng., 20: 1925-1935.

DOI: $10.1007 / \mathrm{s} 12205-015-0790-5$

Andrawes, B. and R. Des Roches, 2007. Comparison between shape memory alloy restrainers and other bridge retrofit devices. J. Bridge Eng., 12: 700-709. DOI: 10.1061/(ASCE)1084-0702(2007)12:6(700)

Bedon, C. and F.A. dos Santos, 2016. FE exploratory investigation on the performance of SMAreinforced laminated glass panels. Adv. Eng. Materials. DOI: 10.1002/adem.201600096

Benmokrane, B., O. Chaallal and R. Masmoudi, 1995. Glass Fibre Reinforced Plastic (GFRP) rebars for concrete structures. Construction and Building Materials, 9: 353-364.

DOI: 10.1016/0950-0618(95)00048-8

Boroschek, R.L., G. Farias, O. Moroni and M. Sarrazin, 2007. Effect of SMA-Braces in a steel frame building. J. Earthquake Eng., 11: 326-342. DOI: $10.1080 / 13632460601125763$

Cao, S., Z. Wu and Z. Wang. 2009. Tensile properties of CFRP and hybrid FRP composites at elevated temperatures. J. Composite Materials, 43: 315-330. DOI: $10.1177 / 0021998308099224$

Dolce, M. and D. Cardone, 2005. Fatigue resistance of SMA-martensite bars subjected to flexural bending, Int. J. Mechanical Sci., 47: 1693-1717. DOI: 10.1016/j.ijmecsci.2005.05.007

dos Santos, F. C. Cismasiu and C. Bedon, 2016b. Smart glazed cable façade subjected to a blast loading. Structures Buildings, 169: 223-232.

DOI: $10.1680 /$ jstbu. 14.00057 
dos Santos, F., C. Bedon and M. Sacadura, 2016a. Adaptive glass panels using shape-memory alloys. Glass Structures Eng., 1: 95-114.

DOI: $10.1007 / \mathrm{s} 40940-01$

Dynalloy, Inc. ${ }^{\circledR} .2016$. www.dynalloy.com

Fiberlines Composites A/S. 2002. Design Manual. 2nd Edn.

Foster, S.K. and L.A. Bisby, 2008. Fire survivability of externally bonded FRP strengthening systems. J. Composites Constructions, 12: 553-561. DOI: 10.1061/(ASCE)1090-0268(2008)12:5(553)

Gattesco, N., C. Amadio and C. Bedon, 2015. Experimental and numerical study on the shear behavior of stone masonry walls strengthened with GFRP reinforced mortar coating and steel-cord reinforced repointing. Eng. Structures, 90: 143-157. DOI: 10.1016/j.engstruct.2015.02.024

Gonilha, J.A., J.R. Correia and F.A. Branco, 2013. Dynamic response under pedestrian load of a GFRP-SFRSCC hybrid footbridge prototype: experimental tests and numerical simulation. Composite Structures, 95: 453-463.

DOI: $10.1016 /$ j.compstruct.2012.07.029

Kodur, V.K.R., L.A. Bisby and M.F. Green. 2007. Guidance for the design of FRP-strengthened concrete members exposed to fire. J. Fire Prot. Eng., 17: 5-26. DOI: 10.1177/1042391507061956

Mc Cormick, J., R. Des Roches, D. Fugazza and F. Auricchio, 2006. Seismic vibration control using superelastic shape memory alloys. J. Eng. Materials Technology, 128: 294-301. DOI: $10.1115 / 1.2203109$

Panigrahi, S.K. and R.D. Rashmi, 2016. Study and analysis of damages in functionally graded adhesively bonded joints of laminated FRP composites: A critical review. Rev. Adhesion Adhesives, 4: 152-165. DOI: $10.7569 /$ RAA.2016.097305

Robert, M. and B. Benmokrane, 2010. Behavior of GFRP reinforcing bars subjected to extreme temperatures. J. Composites Construction, 14: 353-360. DOI: 10.1061/(ASCE)CC.1943-5614.0000092
Savi, M.A., A.S. de Paula and D.C. Lagoudas, 2011. Numerical investigation of an adaptive vibration absorber using shape memory alloys. J. Intelligent Material Systems Structures, 22: 67-80. DOI: $10.1177 / 1045389 X 10392612$

Shook, D.A., P.N. Roschke and O.E. Ozbulut, 2008. Superelastic semi-active damping of a base-isolated structure. Structural Control Health Monitoring, 15: 746-768. DOI: $10.1002 /$ stc. 276

Simulia. 2012. ABAQUS v.6.12 Computer Software and Online Documentation, Dassault Systèmes, Providence, RI, USA.

Tamai, H., Y. Kitagawa and T. Fukuta, 2003. Application of SMA rod to exposed-type column base in smart structural system. Proceedings of SPIE Smart Structures and Materials-Smart Systems and Nondestructive Evaluation for Civil Infrastructures, Aug. 19, San Diego, CA, pp: 169-177. DOI: $10.1117 / 12.482395$

Valarinho, L., J.R. Correia and F.A. Branco, 2013. Experimental study on the flexural behaviour of multi-span transparent glass-GFRP composite beams. Construction Building Materials, 49: 10411053. DOI: $10.1016 /$ j.conbuildmat.2012.11.024

Wilde, K., P. Gardoni and Y. Fujino, 2000. Base isolation system with shape memory alloy device for elevated highway bridges. Eng. Structures, 22: 222-229. DOI: 10.1016/S0141-0296(98)00097-2

Yang, X., Y. Bai, F.J. Luo, X.L. Zhao and F. Ding, 2016. Dynamic and fatigue performances of a largescale space frame assembled using pultruded GFRP composites. Composite Structures, 138: 227-236. DOI: 10.1016/j.compstruct.2015.11.064

Zhang, Y. and S. Zu, 2007. A shape memory alloy-based reusable hysteretic damper for seismic hazard mitigation. Smart Materials Structures, 16: 1603-1623.

Zou, X.K., J.G. Teng, L. De Lorenzis and S.H. Xia, 2007. Optimal performance-based design of FRP jackets for seismic retrofit of reinforced concrete frames. Composites Part B: Engineering, 38: 584-597. DOI: $10.1016 /$ j.compositesb.2006.07.016 